\title{
International Journal of Social Sciences and Management
}

\section{A Rapid Publishing Journal}

ISSN 2091-2986

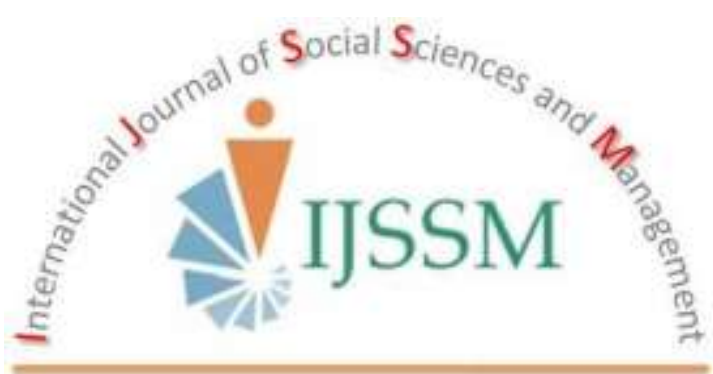

\section{Indexing and Abstracting}

CrossRef, Google Scholar, International Society of Universal Research in Sciences (EyeSource), Journal TOCs, New Jour, Scientific Indexing Services, InfoBase Index, Open Academic Journals Index (OAJI), Scholarsteer, Jour Informatics, Directory of Research Journals Indexing (DRJI), International Society for Research Activity (ISRA): Journal Impact Factor (JIF), Simon Fraser University Library, etc.

Vol- 3(2), April 2016 


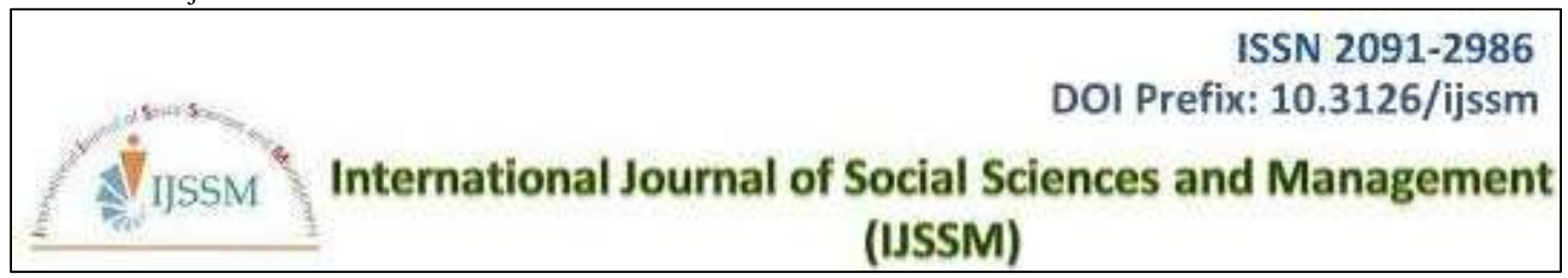

\title{
Research Article VARIATIONS IN ORGANIZATIONAL ROLE STRESS IN DIFFERENT CYCLES OF AGE
}

\author{
Priyanka Girdhar \\ WISDOM, Banasthali Vidhyapith. \\ Email: priyankagirdhar009@gmail.com
}

\begin{abstract}
The present paper seeks to explore variations caused by individual variables categorized in two broad categories i.e. age and dispositionallocus of control. In the present study a sample of 180 employees were selected from different industries. Employees belonging to age group of below 25 years' experience maximum organizational role stress. Second most age group is belonging to age category of 26-35. Employees in age group of above 45 years are reported to be least stressed among employees of all category. Stress level is defined to increase with higher rating on locus scale. Locus of control are somewhat related with internal belief and self-confidence of the individual employees. HR practitioners are advised to consider personality related differences to counter stressors. Psychologists have suggested various practices to build up higher levels of internal locus of control. Practices like ABC theory of emotions, Unconditional Self-Acceptance (USA), Unconditional Others Acceptance (UOA) etc. can prove beneficial in this regards.
\end{abstract}

Keywords: Age; Locus of Control; Role Stagnation; Role Isolation; Role Ambiguity.

\section{Introduction}

Role stress results from problems encountered in role performance. When these problems are confronted or resolved in constructive and positive manner, the resulting role stress gets reduce or gets eliminated partially or completely. The elimination of role stress promotes wellbeing of the role occupant and hence performance and effectiveness of the individual and that of organisation manifolds. The researches have indicated that all employees do not feel same level of role stress. Different level of organisational stress is experienced by employees belonging to different groups categorised on the basis of gender, age, experience etc. (Antoniou et al., 2006).

Occupational stress can arise from a condition when there is a discrepancy between the demands of the workplace and an employees' capability to fulfill these demands. Nevertheless, a stressor may lead to physiological reaction that can strain an employee physically as well as mentally. A variety of factors are responsible for workplace stress. These factors may include tremendous workload, isolation and alienation, extensive working hours, toxic and hazardous working conditions, dearth of autonomy and power, hard and hostile relationships among colleagues and employers, bullying by management and stereotyping, harassment and threat and lack of opportunities and scope for advancement in one's career and professional life. Work stress is generally elaborated and discussed with the help of two contrasting theoretical models i.e. Model 1: Demand control model and Model 2: Effort reward imbalance model. First model i.e. demand control model expresses stress as combination of demand and control situation at work place. According to this theory, work stress is resultant of a distinct work profile. The theory is more concerned with high demand at work place accompanied with low control over work and working environment. Stress may arise when an employee faces excessive job demand (high expectations and responsibilities) and simultaneously low control over job constructs. Second model is based on the work contract. According to effort- reward model, stress is an outcome of high efforts reciprocated by inappropriate or in equivalent rewards in terms of salary, promotion, job security and esteem. It implies that an employee may experience stress if one does not get rewards as per his or her efforts or performance (Dua, 1994).

\section{Literature Review}

Globalization and liberalization has resulted into dramatic shift at work place. Rapidly changing work place scene has increased the expectations from the workforce to optimize output and to enhance competitiveness of the firm. It forces workers to execute multiple tasks in the work station. Employees are in constant pressure to be updated with ever dynamic technologies (Quick et al., 1997). The cumulative effect of these pressures has been 
found to influence work strain. A comprehensive research conducted in UK stated that the bulk of the employees were discontented with the organizational climate which makes them to work overtime. The organizational culture which makes employee unwillingly cope up with huge loads while concurrently meeting construction objectives and time bound goals (Townley, 2000). Role stress is highly related with working at workplace. Various paradigms of functioning living have been found to have a link with stress. Further, other tenets of work are quite stressful. These aspects of work are work overload (Sparks and Cooper, 1999) and role based aspects such as requirement of sufficient power, role overload, role ambiguity and role conflict (Burke, 1988). Emsley (2003) studied numerous goals and employees' work assignment related apprehension. The researcher found that work associated tension is positively related with multiple goals of manager. Further, performance deteriorates as employees follow different goals and the association seems to be non-linear. A set of researchers have explored stress among employees working in Multi-National Companies. Manshor et al. (2003) investigated various sources of job-related anxiety among managers working in MNCs of Malaysia. They reported that workload, working condition, and affiliation at office were the major challenges for the managers in Malaysian MNCs and these factors result into anxiety at office. The paper tends to discusses variations caused in ten different constructs of Organizational Role Stress among employees. The ten constructs are Self-Role Distance, Inter-role Distance, Role Stagnation, Role Isolation, Role Ambiguity, Role expectation conflict, Role Overload, Role Erosion, Resource Inadequacy, Personal inadequacy given by Udai Pareek (1993).

\section{Objective of the Study}

The prime objective of the present research is to find out age and locus of control based description of employees Organizational Role Stress amongst Employees and to study the overall status of different dimensions of Organizational Role Stress amongst employees.

\section{Research Methodology}

The present study is based upon exploratory-cumdescriptive research design. Primary data is collected through two different structured questionnaires. Sample size is 190. To explore Organisational Role Stress a structured questionnaire developed by Pareek (1993) consisting of 50 statements has been used. These 50 statements explore the stress level of the employees under ten different dimensions of ORS. Data has been collected using seven-point scale. Multidimensional Locus of Control Inventory comprising of 24 items has been used to access employees' rating of their locus of control. The inventory uses seven-point scale ranging from -3 to +3 . Random sampling has been used to collect data from various industries. The industries mainly include banking, insurance, textile, sugar, shoe, consultancy, cold drink, rice, etc.

\section{Result and Discussion}

Table 1 elucidates age and locus of control based mean value of organizational role stress among employees. It is reported that mean value for employees belonging to age group of below 25 years' experience maximum organizational role stress $($ mean $=4.77)$. In general, an individual starts career in the age group of 22-25 years and career and life also becomes important for their parents. Second most age group is belonging to age category of 2635 and by the time he or she must have been in industry for 6-8 years. Employees in age group of above 45 years are reported to be least stressed among employees of all category. By the time an individual researches late forties, children leave home for higher studies or for employment. And thus direct parental responsibilities are almost over. Employees with different level locus of control shows significantly varied level of stress. Stress level is defined to increase with higher rating on locus scale. Locus of control are somewhat related with internal belief and selfconfidence of the individual employees. HR practitioners are advised to consider personality related differences to counter stressors. Psychologists have suggested various practices to build up higher levels of self-efficacy and internal locus of control. Practices like ABC theory of emotions, Unconditional Self-Acceptance (USA), Unconditional Others Acceptance (UOA) etc. can prove beneficial in this regards. Further self-efficacy is reported to flourish in an environment of encouragement and mutual trust. Thus researcher suggests conducive and open environment can help to heal stressed employees. Now different dimensions of ORS are subjected to individual difference based variation analysis.

Table 1: Frequency and Mean of Respondents

\begin{tabular}{|l|l|l|l|}
\hline Variable & Category & Frequency & Mean \\
\hline \multirow{4}{*}{ Age } & Below 25 & 30 & 4.77 \\
\cline { 2 - 4 } & $26-35$ & 74 & 4.52 \\
\cline { 2 - 4 } & $36-45$ & 50 & 4.38 \\
\cline { 2 - 4 } & Above 45 & 36 & 4.23 \\
\hline \multirow{2}{*}{$\begin{array}{l}\text { Locus of Control } \\
\text { Mean value on } \\
\text { Leverson scale) }\end{array}$} & -3 to -1 & 29 & 4.78 \\
\cline { 2 - 4 } & -1 to 1 & 48 & 4.57 \\
\cline { 2 - 4 } & 1 to 3 & 113 & 4.41 \\
\hline
\end{tabular}

Factor age is subjected to ANOVA for all ten dimensions of Organisational Role Stress. Six dimensions of Organisational Role Stress are observed to vary significantly among employees of different age group. Mean value of ORS is reported higher for young employees (Table-1). Dimensions showing significant 
variations like Role Ambiguity, Role Overload, Resource Inadequacy and Role Isolation are clearly related with younger generation. Thus young employees could be relived from stress through adopting mechanism that deals with these dimensions of stress specifically. For inference HR manager often induct a stressed youngster in a team to relieve one from role overload and resource inadequacy stressors (Table 2). In similar way practical and effective methods could be devised to counter various stressors specific to a particular age group (Fig 1)

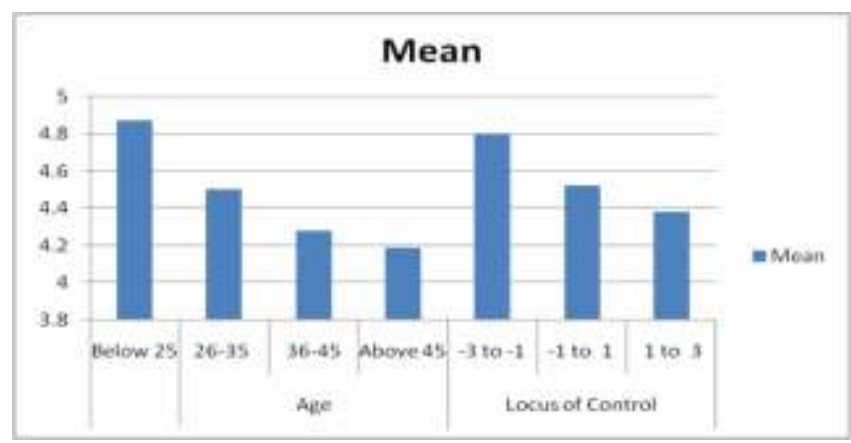

Fig. 1: Age and Locus of Control based variations among ORS in employees

Table 2: Age Variations in Dimensions of Organizational Role Stress

\begin{tabular}{|l|l|l|l|}
\hline \multirow{2}{*}{$\begin{array}{l}\text { S. } \\
\text { N. }\end{array}$} & Dimensions of Organizational & \multicolumn{2}{|l|}{ Age } \\
\cline { 3 - 4 } & & $\begin{array}{l}\text { F- } \\
\text { Value }\end{array}$ & Sig. \\
\hline 1 & Inter Role Distance (IRD) & 0.851 & 0.068 \\
\hline 2 & Role Stagnation (RS) & 0.790 & 0.059 \\
\hline 3 & Role Expectation Conflict (REC) & 4.02 & 0.041 \\
\hline 4 & Role Erosion (RE) & 0.521 & 0.099 \\
\hline 5 & Role Overload (RO) & 3.96 & 0.021 \\
\hline 6 & Role Isolation (RI) & 4.40 & 0.004 \\
\hline 7 & Personal Inadequacy (PI) & 0.652 & 0.078 \\
\hline 8 & Self-Role Distance (SRD) & 5.11 & 0.001 \\
\hline 9 & Role Ambiguity (RA) & 3.99 & 0.049 \\
\hline 10 & Resource Inadequacy (RID) & 3.60 & 0.031 \\
\hline
\end{tabular}

In case of locus of control six out of ten dimensions of stress shows significant fluctuations. The constructs of ORS are Inter Role Distance, Role Expectation Conflict, Role Overload, Self-Role Distance, Role Ambiguity and Resource Inadequacy (value of $\mathrm{p}$ is lesser than .05 for all these constructs at $95 \%$ level of significance). Employees of all age categories are equally stressed for four constructs of organizational role stress. The four paradigms are Role Stagnation, Role Erosion, Role Isolation and personal inadequacy. An employee with higher level of self-belief, self-motivation, will power and determination is better equipped to deal with stressors
Role Overload, Inter Role distance and Self Role Distance. Strong inner belief will help an individual to fulfill expectation from various parts of one's life (Table 3).

Table 3: Locus of Control Variations in Dimensions of Organizational Role Stress

\begin{tabular}{|l|l|l|c|}
\hline \multirow{2}{*}{$\begin{array}{l}\text { S. } \\
\text { N. }\end{array}$} & \multirow{2}{*}{$\begin{array}{l}\text { Dimensions of Organizational } \\
\text { Role Stress }\end{array}$} & \multicolumn{2}{|l|}{$\begin{array}{l}\text { Locus of } \\
\text { Control }\end{array}$} \\
\cline { 3 - 4 } & & $\begin{array}{l}\text { F- } \\
\text { Value }\end{array}$ & Sig. \\
\hline 1 & Inter Role Distance (IRD) & 1.250 & $\mathbf{. 0 4 8}$ \\
\hline 2 & Role Stagnation (RS) & 0.147 & .897 \\
\hline 3 & Role Expectation Conflict (REC) & 6.250 & $\mathbf{. 0 1 2}$ \\
\hline 4 & Role Erosion (RE) & 0.587 & .587 \\
\hline 5 & Role Overload (RO) & 3.570 & $\mathbf{. 0 3 3}$ \\
\hline 6 & Role Isolation (RI) & 0.058 & 2.35 \\
\hline 7 & Personal Inadequacy (PI) & 0.554 & .054 \\
\hline 8 & Self-Role Distance (SRD) & 3.110 & $\mathbf{. 0 2 7}$ \\
\hline 9 & Role Ambiguity (RA) & 1.120 & $\mathbf{. 0 4 4}$ \\
\hline 10 & Resource Inadequacy (RID) & 1.250 & $\mathbf{. 0 4 8}$ \\
\hline
\end{tabular}

\section{Conclusion}

At last it can be concluded that Employees belonging to age group of below 25 years' experience maximum organizational role stress. Second most age group is belonging to age category of 26-35. Employees in age group of above 45 years are reported to be least stressed among employees of all category. Stress level is defined to increase with higher rating on locus scale. Locus of control are somewhat related with internal belief and selfconfidence of the individual employees. HR practitioners are advised to consider personality related differences to counter stressors. Psychologists have suggested various practices to build up higher levels of internal locus of control. Practices like ABC theory of emotions, Unconditional Self-Acceptance (USA), Unconditional Others Acceptance (UOA) etc. can prove beneficial in this regards.

\section{References}

Antoniou A, Polychroni F and Vlachakis AN (2006) Gender and age differences in occupational stress and professional burnout between primary and high-school teachers in Greece. Journal of Managerial Psychology 21(7): 682690.

Burke RJ (1998) Work and non-work stressors and well-being among police officers: The role of coping. Anxiety, stress and coping 11(4): 345-362.

Dua JK (1994) Job stressors and their effects on physical health, emotional health, and job satisfaction in a university. Journal of Educational Administration 32(1): 59-78. 
Emsley D (2003) Multiple goals and managers' job-related tension and performance. Journal of Managerial Psychology 18(4): 345-356.

Manshor AT, Fontaine R and Choy CS (2003) Occupational stress among managers: a Malaysian survey. Journal of managerial psychology 18(6): 622-628.

Pareek U (1993) Motivating Organisational Roles: Role Efficacy Approach, Jaipur: Rawat Publication.

Quick JC, Camara WJ, Hurrell Jr JJ, Johnson JV, Piotrkowski CS, Sauter SL and Spielberger CD (1997) Introduction and historical overview. Journal of Occupational Health Psychology 2(1): 3.

Sparks K and Cooper CL (1999) Occupational differences in the work-strain relationship: Towards the use of situation-specific models. Journal of Occupational and Organizational Psychology 72(2): 219-229.

Townley G (2000) Long hours culture causing economy to suffer. Management Accounting 78(6): 3-5 